\title{
A Series Resonant Converter for Arc-Striking Applications
}

\author{
Jan A. Ferreira, Member, IEEE, and Johannes A. Roux
}

\begin{abstract}
Initiation of a plasma conduction state requires a relatively large voltage to ionize the gas. A new version of the series resonant converter is proposed that uses the magnetizing inductance of the transformer for resonance. This converter is not suitable for most power supply applications, but the unique load characteristics associated with plasma loads make this type of converter well suited for arc striking, while allowing safe operation during the plasma state. A feature of the resonant converter is that the controller need not be complex, thus making it suitable for application in competitive industrial systems. Possible transformer configurations are investigated, which include an air core and a number of ferrite-cored transformers. The series resonant converter with the best-suited transformer is verified experimentally in a tungsten inert gas welding application.
\end{abstract}

Index Terms-Resonant power conversion, transformers, welding.

\section{INTRODUCTION}

$\mathbf{T}$ HE electric arc finds widespread application, ranging from electroheating to lighting applications. Common to these applications is the fact that a high initial voltage is required to ionize the gas before the plasma state can commence. Once ionized, the arc is maintained by supplying current at a reduced voltage. In lighting applications, a heating filament is often included to reduce this striking voltage, but such an approach is not practical in electroheat applications, such as welding and chemical plasma burners.

The power supply must, thus, be able to provide both output characteristics, as shown on the VI curve in Fig. 1. This is an inconvenient situation when using a single power electronic converter, since the switching devices must be dimensioned to block the full voltage and carry the full current. An alternative is to use two separate converters, one for supplying the high current and the other for supplying the high voltage. These two converters can either be connected in series or in parallel, depending on the requirements of the application.

Figs. 2 and 3 show a number of possible connection methods for the high-current low-voltage converter and the high-voltage low-current converter. Diode rectifiers are needed for dc, and a transformer coupling is required when the output is ac. The secondary on the transformers of the high-voltage converter must be able to carry the full-load current in the series-

Manuscript received January 15, 1997; revised April 25, 1998. Abstract published on the Internet May 1, 1998.

J. A. Ferreira is with the Faculty of Electrical Engineeering, Delft University of Technology, 2600 GA Delft, The Netherlands.

J. A. Roux is with Research and Development, Iron and Steel Corporation of South Africa, Pretoria West, 0002 South Africa.

Publisher Item Identifier S 0278-0046(98)05679-2.

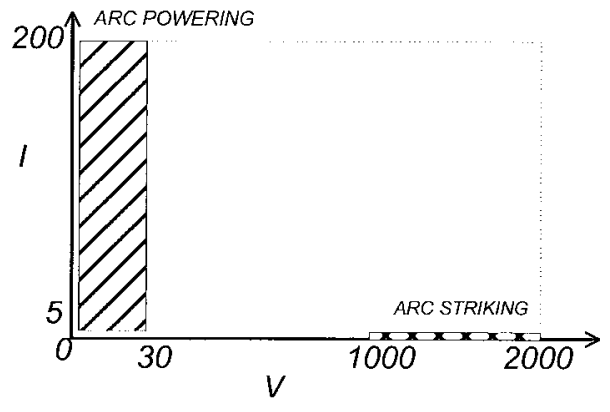

Fig. 1. Typical output voltage versus output current ranges for arc striking and arc powering.

connected composite converters, and the rectifier diodes must be able to carry the full current and block the high voltage. The ac sources can be decoupled by including filters, using an inductor $L$ and a capacitor $C$, as indicated in some of the circuits.

For welding applications the output of the high-voltage converter must be high-frequency ac for safety reasons [1]. The transformer not only steps up the voltage, but also provides the very important mains isolation. Of the four possible candidate high-voltage ac topologies [Figs. 2(b) and (d) and 3(b) and (d)], the series-connected versions shown in Fig. 2(b) and (d) are preferred for the following two reasons.

1) Additional decoupling capacitor $C$ and decoupling inductor $L$ [Fig. 3(b) and (d)] are not required, representing a component saving.

2) $L, C$ and the output of the high-current converter [Fig. 3 (b) and (d)] load the high-voltage converter during open circuit, and this affects the rating of the converter.

A number of high-frequency ac sources are subsequently described that can be used in any of the above four topologies. Many converter topologies suitable for providing the high current and low voltage can be found in the literature [2]-[4]. These include high-frequency switching converters and also use high leakage inductance line frequency transformers.

The electric arc presents a very high impedance value during the ionization or arc striking interval that changes to a low impedance, which may approach a short circuit, in the presence of an arc plasma. The high-voltage converter, therefore, has to cater to a large load impedance variation. The series-connected topologies shown in Fig. 2(b) and (d) additionally require a secondary winding of the output transformer, which has to carry the full welding current. In order to keep the $I^{2} R$ losses 


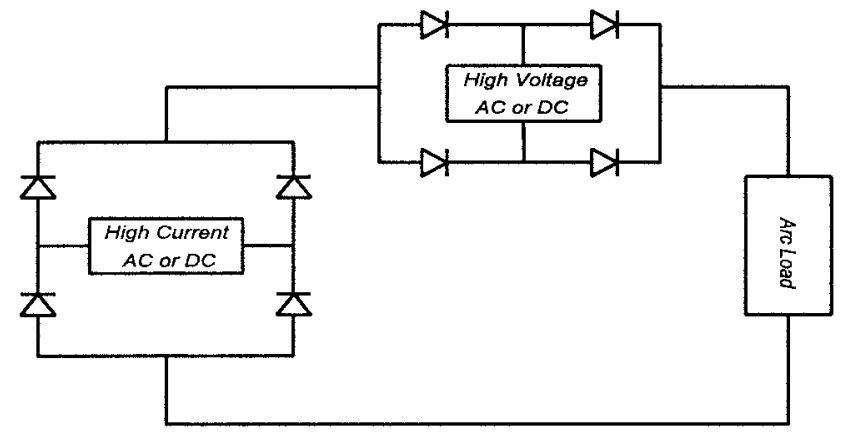

(a)

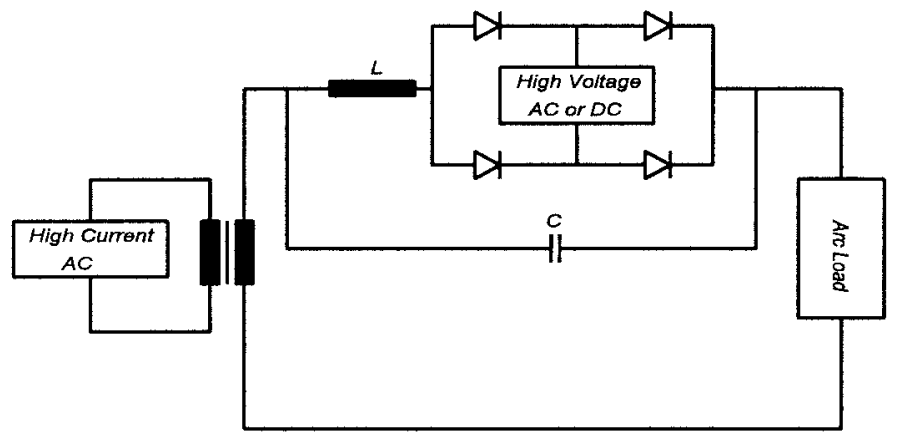

(c)

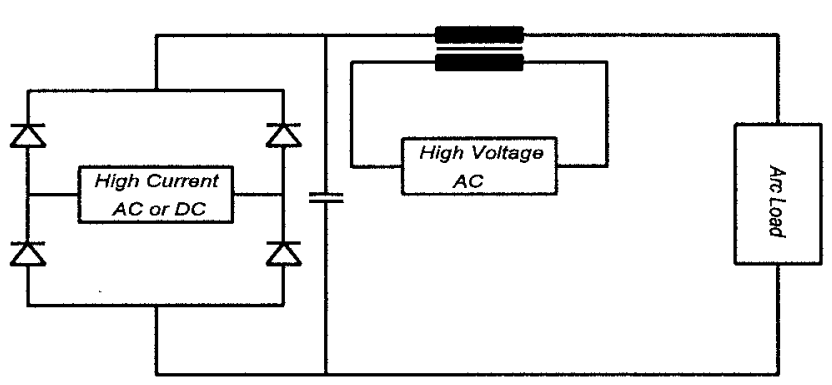

(b)

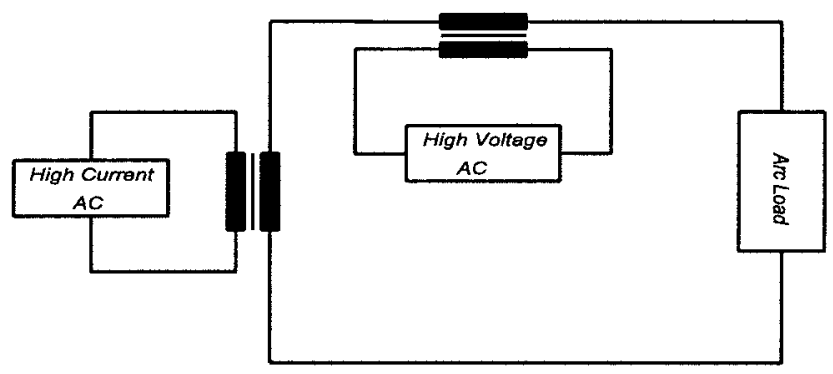

(d)

Fig. 2. Series-connected topologies of a high-current low-voltage converter and a high-voltage low-current converter.

down to an acceptable value, the number of the secondary turns needs to be minimized. Consequently, the high-voltage arc striking converter is operated at the maximum possible frequency.

\section{SElection OF A TOPOLOGY FOR THE SERIES-CONNECTED CONVERTER}

The high-voltage low-current resonant converter will typically be sourced by the utility grid; therefore, a clampedvoltage voltage-sourced series resonant topology in the halfbridge configuration is preferred, in order to keep the voltage stresses low. The series-connected circuits of Fig. 2(b) and (d) lend themselves to using the quality factor of a series $L C$ circuit to build up the large voltage required for arc striking. A series resonant converter [5], [6] operated close to resonant frequency can generate a large voltage across the capacitor and inductor.

The following three different possibilities exist:

1) series loaded, series resonant;

2) parallel capacitive-loaded, series resonant;

3) parallel inductive-loaded, series resonant.

The series resonant converter can operate at zero load [2], but cannot provide a high output voltage during no load. The parallel capacitive-loaded converter can provide a high zeroload output voltage, but suffers from increased current during plasma operation if the switching frequency remains constant [2]. It also needs two large capacitors to split the supply and an external inductance.

The parallel inductive-loaded series resonant converter is the preferred topology, because the magnetizing inductance of the transformer can be used as the resonant inductor, thus reducing the number of components. At first glance, the converter, as shown in Fig. 4, may not seem to be short-circuit proof, but consider the following.

The core of the transformer is saturated by the high current which maintains the arc during the plasma state, which means the resonant frequency increases. If the converter switching frequency is kept constant, the converter will operate well below its resonant frequency. The energy, the current, and the voltage in the resonant $L C$ tank will, therefore, be small, and overall losses in the converter are, in fact, reduced.

\section{CONVERTER OPERATION}

The arc-striking converter uses a series resonant parallel inductive-loaded converter that is connected in series with the load, as shown in Fig. 4. A high-current converter supplies a welding current that typically ranges between 100-300 A. The combined inductance of the transformer and the load forms a series resonant circuit with the parallel combination of capacitors $C 1$ and $C 2$. The converter operates under one of two conditions, namely, an open circuit condition when the gas medium around the electrodes is being ionized to initiate the arc [Mode 1], and a plasma conduction condition when the arc supports a large current [Mode 2].

A high secondary voltage is obtained during Mode 1 operation by switching the converter close to the resonant frequency, using the quality factor of the resonant $L C$ tank to amplify the voltage. The electrode is about $10 \mathrm{~mm}$ from the workpiece and the secondary circuit is open circuit. The equivalent circuit presented by the transformer is shown in Fig. 5(a). The 


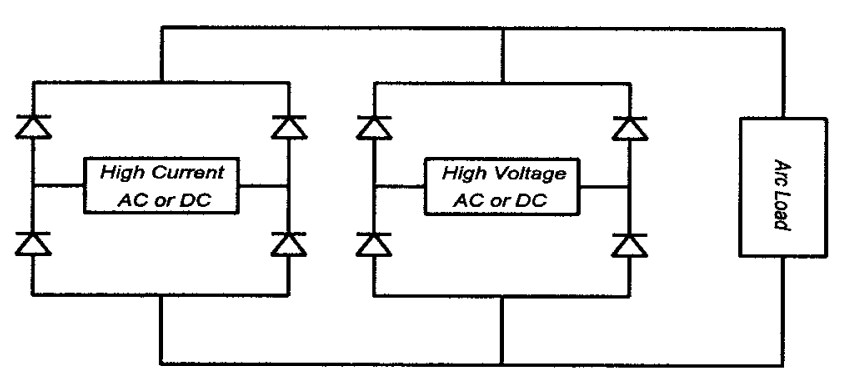

(a)

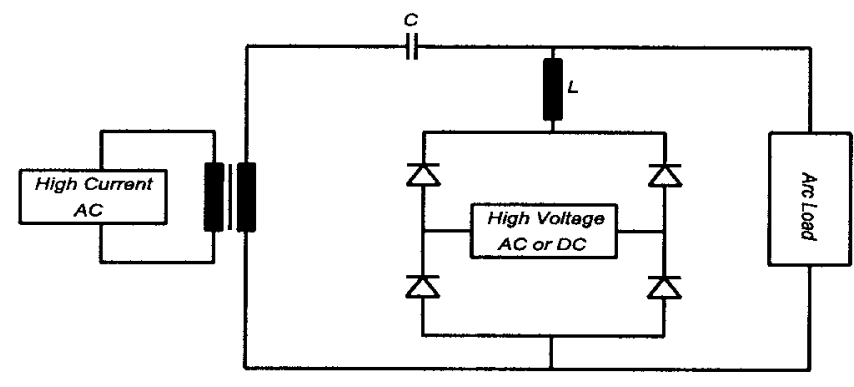

(c)

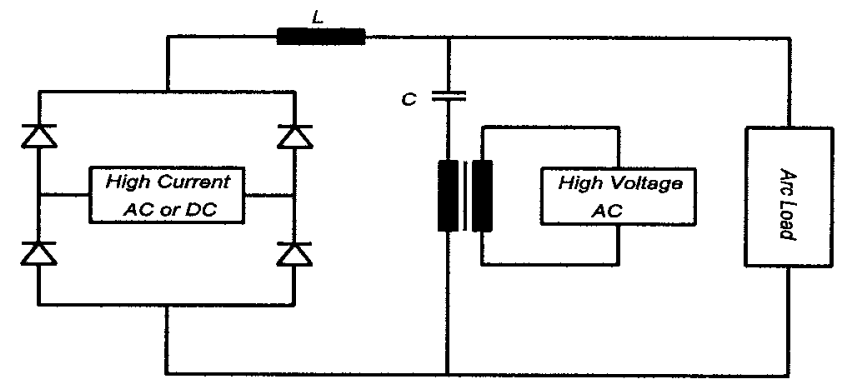

(b)

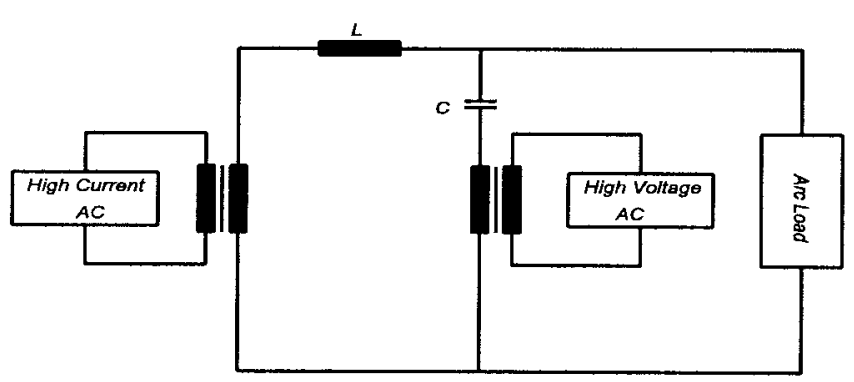

(d)

Fig. 3. Parallel-connected topologies of a high-current low-voltage converter and a high-voltage low-current converter.

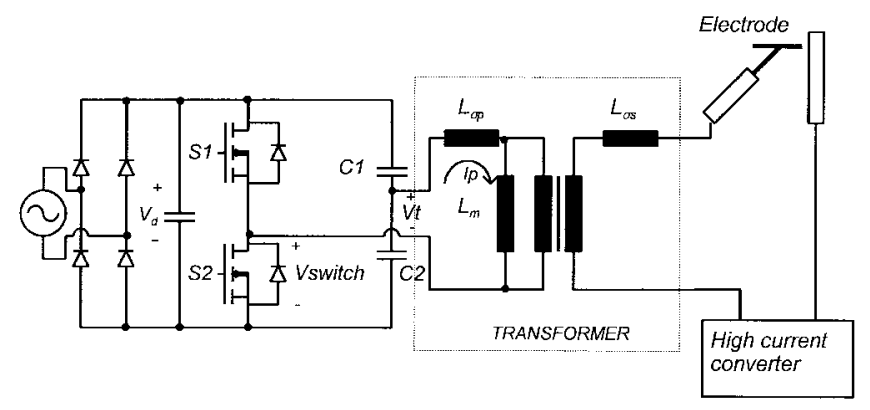

Fig. 4. The parallel inductive-loaded series resonant converter used as the arc-striking converter.

magnetizing inductance dominates, and the input impedance of the transformer is given by the following equations:

$$
Z_{1}=R_{1}+j \omega L_{1}
$$

where

$$
\begin{aligned}
& R_{1}=R_{\sigma p 1}+\frac{1}{R_{c l} \cdot\left[\frac{1}{R_{c 1}^{2}}+\frac{1}{\left(\omega^{2} \cdot L_{m 1}^{2}\right)}\right]} \\
& L_{1}=L_{\sigma p 1}+\frac{1}{\omega^{2} \cdot L_{m 1} \cdot\left[\frac{1}{R_{c 1}^{2}}+\frac{1}{\left(\omega^{2} \cdot L_{m 1}^{2}\right)}\right]} .
\end{aligned}
$$

Mode 2 operation occurs when the arc is powered by the high-current converter. A voltage that typically ranges between 20-30 V appears across the electrodes. The voltage current relationship of a plasma is known to be complex, but, since the arc voltage is typically less than $10 \%$ of the applied voltage to the transformer referred primary in this application, an accurate value is not important and the arc voltage is represented by a constant voltage source, as indicated in Fig. 5(b). The highcurrent converter acts as a current source, but is shunted by a filter capacitor at the output. Consequently, the transformer load presents an effective short circuit for the high-frequency ac, as indicated by the dotted line in Fig. 5(b).

During Mode 2 operation, the core is saturated by the high welding current that flows through the secondary winding of the transformer, and the value of $L_{m}$ is, therefore, significantly reduced. In parallel to the magnetizing inductance appears the secondary impedance $\left(R_{\mathrm{sec}}+j \omega L_{\mathrm{sec}}\right)$, which is formed by the secondary leakage impedance of the transformer, the arc resistance, and the impedance of the welding cables. The input impedance of Mode 2 is given by the following equation:

$$
Z_{2}=R_{2}+j \sigma L_{2}
$$

where

$$
\begin{aligned}
& R_{2}=R_{\sigma p 2}+\frac{\left[\frac{R_{\mathrm{sec}}}{\left|Z_{\mathrm{sec}}\right|^{2}}+\frac{1}{R_{c 2}}\right]}{\left[\frac{R_{\mathrm{sec}}}{\left|Z_{\mathrm{sec}}\right|^{2}}+\frac{1}{R_{c 2}}\right]^{2}-\left[\omega \cdot \frac{L_{\mathrm{sec}}}{\left|Z_{\mathrm{sec}}\right|^{2}}+\frac{1}{\omega \cdot L_{m 2}}\right]^{2}} \\
& L_{2}=L_{\sigma p 2}+\frac{\frac{L_{\mathrm{sec}}}{\left|Z_{\mathrm{sec}}\right|^{2}} \frac{1}{\left(\omega \cdot L_{m 2}\right)}}{\left[\frac{R_{\mathrm{sec}}}{\left|Z_{\mathrm{sec}}\right|^{2}}+\frac{1}{R_{c 2}}\right]^{2}-\left[\omega \cdot \frac{L_{\mathrm{sec}}}{\left|Z_{\mathrm{sec}}\right|^{2}}+\frac{1}{\omega \cdot L_{m 2}}\right]^{2}}
\end{aligned}
$$

with

$$
\left|Z_{\mathrm{sec}}\right|=\sqrt{R_{\mathrm{sec}}+\omega^{2} L_{\mathrm{sec}} 2} .
$$




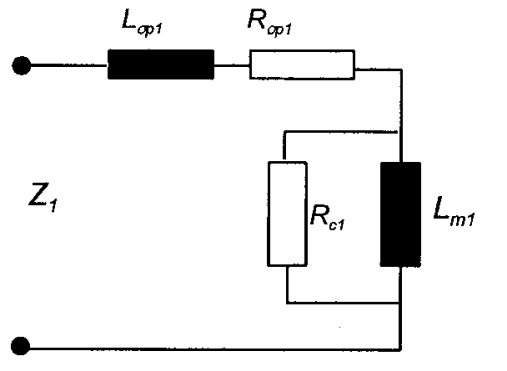

(a)

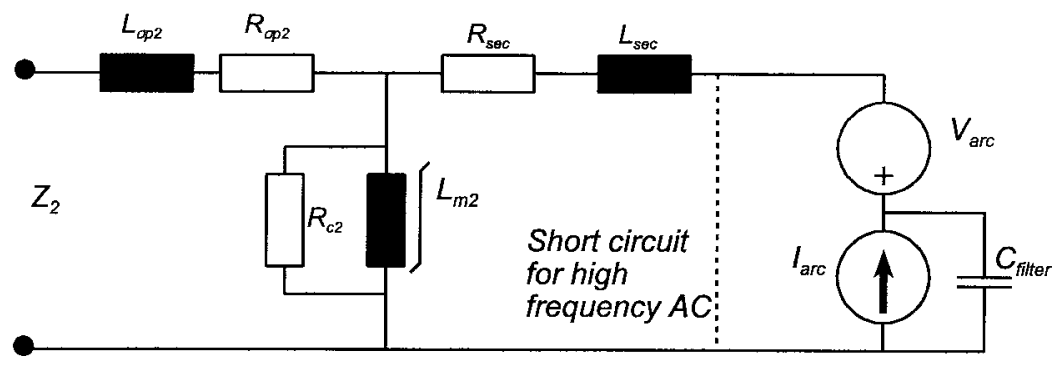

(b)

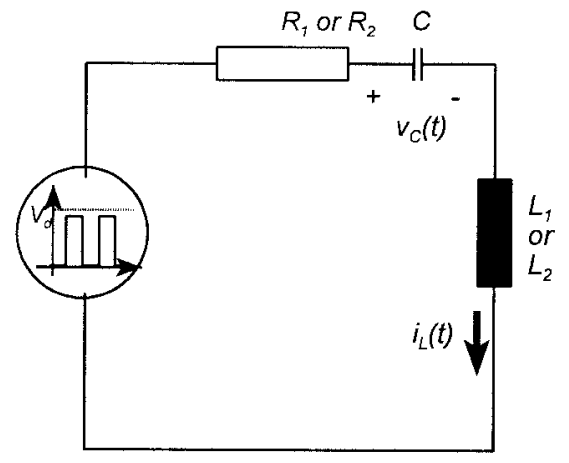

(c)

Fig. 5. Equivalent circuit of the series resonant converter.

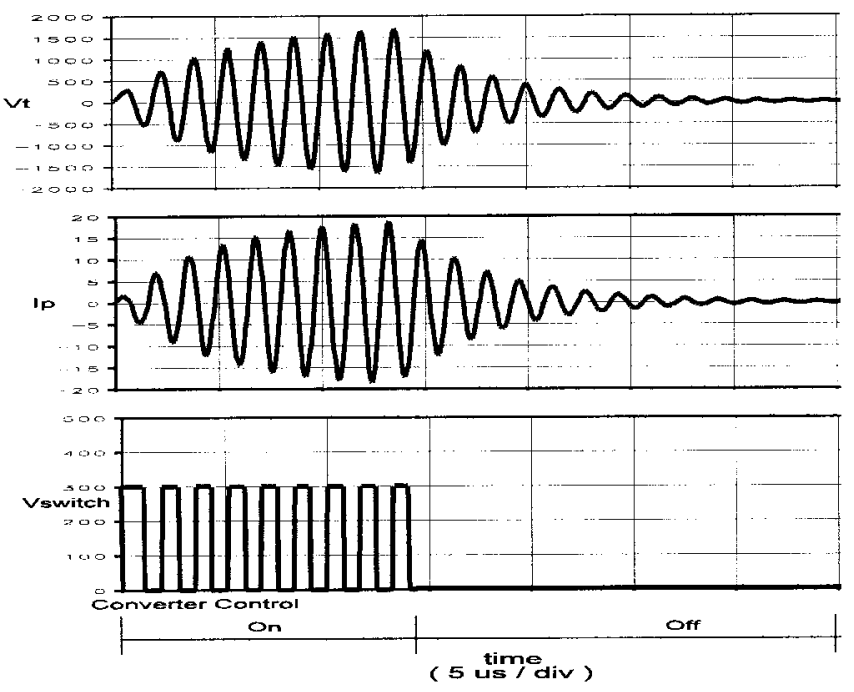

(a)
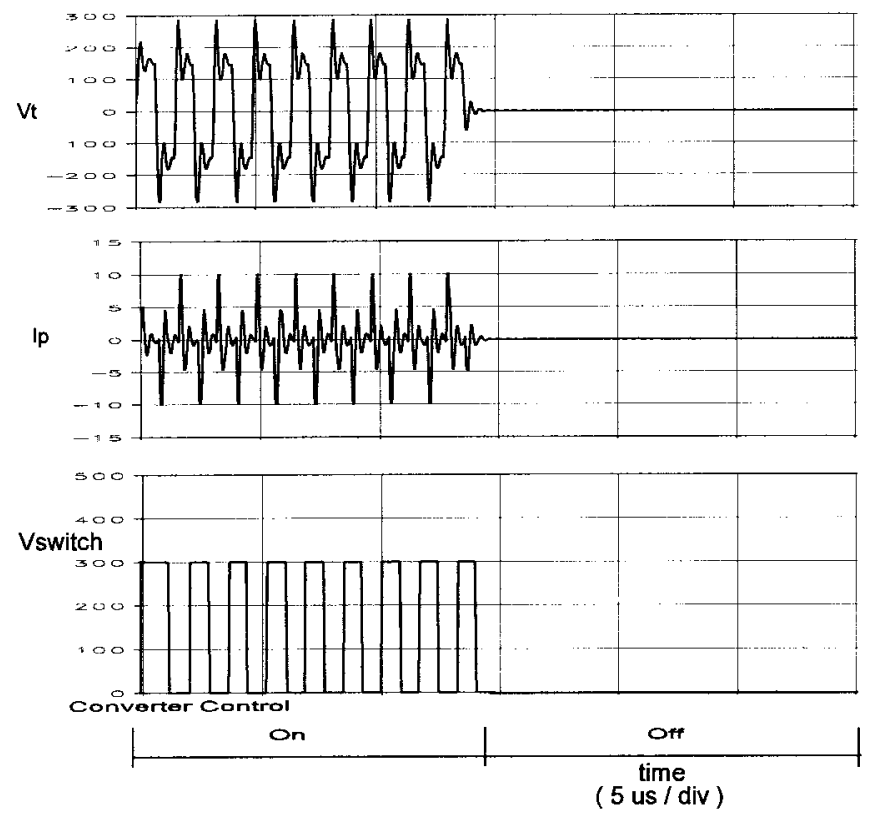

(b)

Fig. 6. Typical waveforms.

During Modes 1 and 2 operation, the transformer excitation differs completely, to such an extent that it is not possible to use one equivalent circuit model for both these conditions. In practice, saturation of the transformer during plasma conduction (Mode 2) substantially changes the values of the various circuit elements, and the ac resistances $R_{\sigma p 1}$ and $R_{\sigma p 2}$, as well as the leakage inductances $L_{\sigma p 1}$ and $L_{\sigma p 2}$ of the two equivalent circuits in Fig. 5(a) and (b), will be different.

The transistors $S 1$ and $S 2$ are both switched alternatively at a constant duty cycle, providing a 50\% duty cycle pulse train ( $V_{\text {switch }}$ in Fig. 5). The equivalent circuit comprises a series $R L C$ circuit powered by a square-wave voltage source, 
as shown in Fig. 5(c). The value of the resistance or inductance is then given by (1) and (2) or (5) and (6), depending on which mode the circuit operates in. A high secondary voltage is obtained during Mode 1 operation by switching the converter close to the resonant frequency, using the quality factor of the resonant $L C$ tank to amplify the transformer voltage. The input inductance is significantly lower during Mode 2 operation, which, in turn, reduces the resonant frequency. The switching frequency stays at the Mode 1 setting all the time and, thus, during Mode 2, the switching frequency is lower than the switching frequency.

Mode 1 operation corresponds to the so-called "integral cycle mode," as described in [7], and a similar method of analysis can be applied. However, in this instance, we have to deal with a varying resonant frequency. The current through the inductor and voltage across the capacitor is calculated repeatedly over each switching cycle using the following equations:

$$
\begin{aligned}
i_{L}(t)= & e^{-\alpha t}\left[I_{L O} \cos \left(\omega_{d} t\right)\right. \\
& +\left(\frac{V_{\text {switch }}-V_{C O}}{L \omega_{d}}-\frac{I_{L O} \alpha}{\omega_{d}}\right) \sin \left(\omega_{d} t\right) \\
v_{C}(t)= & V_{\text {switch }}-e^{-\alpha t}\left[\left(V_{\text {switch }}-V_{C O}\right) \cos \left(\omega_{d} t\right)\right. \\
& +\left(V_{\text {switch }}-V_{C O}\right)\left(\frac{\alpha}{\omega_{d}}-\frac{L_{L O}}{\omega_{d} C}\right) \sin \left(\omega_{d}\right)
\end{aligned}
$$

with

$$
\begin{aligned}
\alpha & =\frac{R}{2 L} \\
\omega_{d} & =\sqrt{\frac{1}{L C}-\alpha^{2}}
\end{aligned}
$$

while $V_{C O}$ and $I_{L O}$ are the initial values of capacitor voltage and inductor current, and $V_{\text {switch }} \equiv 0$ or $V d$, depending on the half cycle.

Peak arc-striking voltage is not required continuously, and the converter is operated at a duty cycle of typically $10 \%$, without losing arc-striking performance. In Fig. 6(a), a typical cycle under Mode 1 operation is shown. Burst control is applied to allow the transformer to operate within its thermal rating, while, at the same time, using the full flux excursion of the transformer to reduce the number of turns on the high-current secondary. When the converter is turned on, the voltage and current build up to a predetermined value, and then the converter is turned off. The energy in the tank decays exponentially during the off state of the converter. The cycle is repeated until the arc is struck. During plasma conduction, the burst-mode pulse train is maintained, but, since the resonant frequency changes, the amplitude of the current and voltage waveforms become smaller. The Mode 2 waveforms are shown in Fig. 6(b), indicating how each switching transient excites the resonant tank, after which the oscillations decay exponentially. If the arc breaks for any reason, the converter will automatically return to Mode 1 operation, and a high output voltage will once again be applied to restrike the arc.

\section{TRANSFORMER CONFIGURATIONS}

The analysis of the transformer is complicated, due to core saturation and eddy-current losses, particularly in the large conductors of the high-current secondary winding. Four different transformer configurations were constructed and experimentally evaluated. The transformers are shown in Fig. 7, and the Appendix describes the method used to obtain the values of the equivalent inductance and resistance of the transformer during each mode of operation. The volume, weight, and manufacturability of the transformers are important factors for the assessment. The transformer has the following special requirements.

1) It is a high-voltage transformer, which means that the isolation must be good.

2) The secondary winding must be able to carry the welding current, which can be from 5 to $200 \mathrm{~A}$, and must be designed accordingly.

The following guidelines were used for designing the transformers.

1) Welding cable is used on the secondary winding, and the copper cross-sectional area is, therefore, determined by the output current rating of the welder. The secondary takes up most of the space in the winding window, and the number of secondary turns $N_{s}$ is determined by the available space.

2) A suitable core size that can handle the integral of the output voltage size is selected. A higher than normal flux density for a given frequency is used, and the losses are contained by adjusting the duty cycle of the burst operation.

3) The turns ratio, as well as the quality factor, determine the output voltage on the secondary during Mode 1 operation. When the number of primary turns is decreased to achieve a higher turns ratio, the quality factor deteriorates at the same time. Consequently, the output voltage is not as sensitive to the turns ratio as one would expect. During the investigation, the turns ratio of $1: 1$ was chosen.

4) The Mode 1 resonant inductance and capacitance were selected based on the requirements for frequency and resonant tank characteristic impedance. The airgap is adjusted to achieve a desirable $L_{1}$.

The advantages of the E65-cored transformer [Fig. 7(a)] are that it is compact and light. The disadvantage is that the window area of the core is small, meaning that 1-mm-thick foil winding is required for the secondary winding, which leaves little space for interwinding isolation.

The advantage of the 192-cored transformer [Fig. 7(b)] is a large magnetic cross-sectional area, which means that fewer turns are needed. The window area is also large enough to use isolated cable on the secondary. The disadvantage of this transformer is that it is large and heavy.

The advantage of the U52-cored transformer [Fig. 7(c)] is a large window area, which makes a high number of turns possible. The disadvantage, however, is that construction is complicated by the large number of stacked cores. 


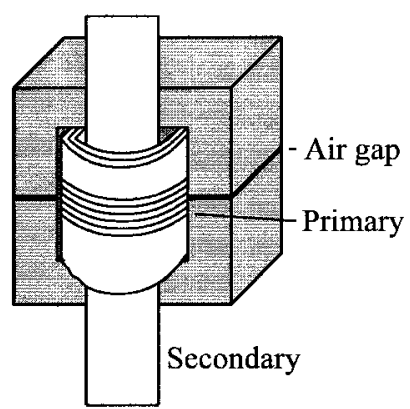

$\begin{array}{ll}\text { Effective magnetic area: } & 532 \mathrm{~mm}^{2} \\ \text { Effective volume of the core } & 78200 \mathrm{~mm}^{3} \\ \text { Effective window area : } & 280 \mathrm{~mm}^{2} \\ \text { Air gap: } & 0.5 \mathrm{~mm} \\ \text { Mass of transformer: } & 703 \mathrm{~g} . \\ \mathrm{L}_{\text {eq1 }}=1.81 \mu \mathrm{H} & \mathrm{R}_{\text {eq1 }}=1.80 \Omega \\ \mathrm{L}_{\mathrm{e}: 2}=0.54 \mu \mathrm{H} & \mathrm{R}_{\mathrm{eq} 2}=0.99 \Omega\end{array}$

(a)

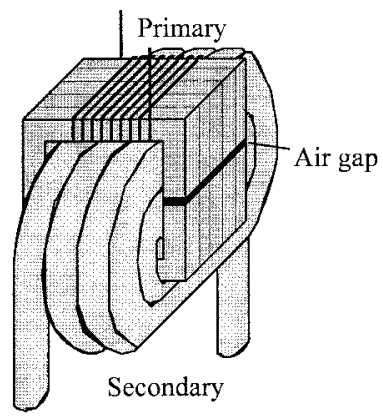

$\begin{array}{ll}\text { Effective magnetic area: } & 465 \mathrm{~mm}^{2} \\ \text { Effective volume of the core : } & 75500 \mathrm{~mm}^{3} \\ \text { Effective window area : } & 885 \mathrm{~mm}^{2} \\ \text { Air gap: } & 0.5 \mathrm{~mm} \\ \text { Mass of transformer: } & 1000 \mathrm{~g} . \\ \mathrm{L}_{\mathrm{eq} 1}=1.59 \mu \mathrm{H} & \mathrm{R}_{\mathrm{cq} 1}=1.70 \Omega \\ \mathrm{L}_{\mathrm{cq} 2}=0.43 \mu \mathrm{H} & \mathrm{R}_{\mathrm{eq} 2}=0.88 \Omega\end{array}$

(c)

Fig. 7. Transformer configurations.

Lastly, the air-cored transformer shown in Fig. 7(d) was constructed. It features a coaxial conductor to achieve good coupling between primary and secondary. The advantage of this transformer is that it does not use a magnetic core. The disadvantages are the size and weight of the windings and the electromagnetic interference that it creates. Also, due to its physical size, the inductance values had to be compromised, compared to the magnetic-cored transformers.

As can be seen from the values of the equivalent inductance and resistance for the different modes of operation, all of the transformers are suitable for the application. The air-cored transformer also functioned well during plasma conduction (Mode 2), despite the absence of a core that saturates. This

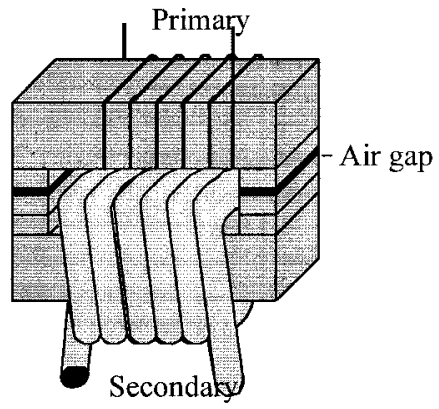

$\begin{array}{lc}\text { Effective magnetic area: } & 826 \mathrm{~mm}^{2} \\ \text { Effective volume of the core : } & 38300 \mathrm{~mm}^{3} \\ \text { Effective window area : } & 680 \mathrm{~mm}^{2} \\ \text { Air gap: } & 0.5 \mathrm{~mm} \\ \text { Mass of transformer: } & 1103 \mathrm{~g} . \\ \mathrm{L}_{\mathrm{eq} 1}=2.20 \mu \mathrm{H} & \mathrm{R}_{\mathrm{eq} 1}=2.00 \Omega \\ \mathrm{L}_{\mathrm{eq} 2}=0.45 \mu \mathrm{H} & \mathrm{R}_{\mathrm{eq} 2}=0.91 \Omega\end{array}$

(b)

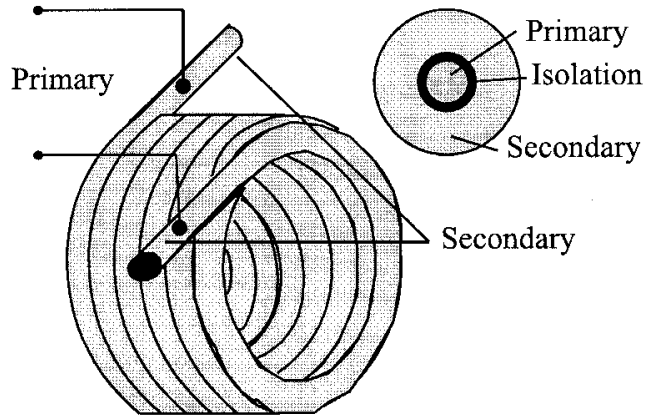

Radius of windings : $\quad 120 \mathrm{~mm}$

Mass of transformer :

$1684 \mathrm{~g}$

$\mathrm{L}_{\mathrm{eq} 1}=0.56 \mu \mathrm{H}$

$\mathrm{R}_{\text {eq1 }}=1.01 \Omega$

$\mathrm{L}_{\text {eq2 }}=0.11 \mu \mathrm{H}$

$\mathrm{R}_{\mathrm{eq} 2}=0.45 \Omega$

(d) is because the leakage inductance on the secondary is smaller than the magnetizing inductance, meaning that the equivalent inductance during Mode 2 operation is smaller than the equivalent inductance during Mode 1 operation.

Choosing the best transformer configuration is influenced by the specific application. If weight and size are the most important factors, then the E65-cored transformer is the best. If cost and manufacturability are the most important factors, then the air-cored transformer or the I92-cored transformer will be best suited. Even though the air-cored transformer has the lowest equivalent resistance, its inductance is much smaller than its magnetic-cored counterparts. The frequency of 800 $\mathrm{kHz}$ is not yet high enough to make it a viable proposition. 

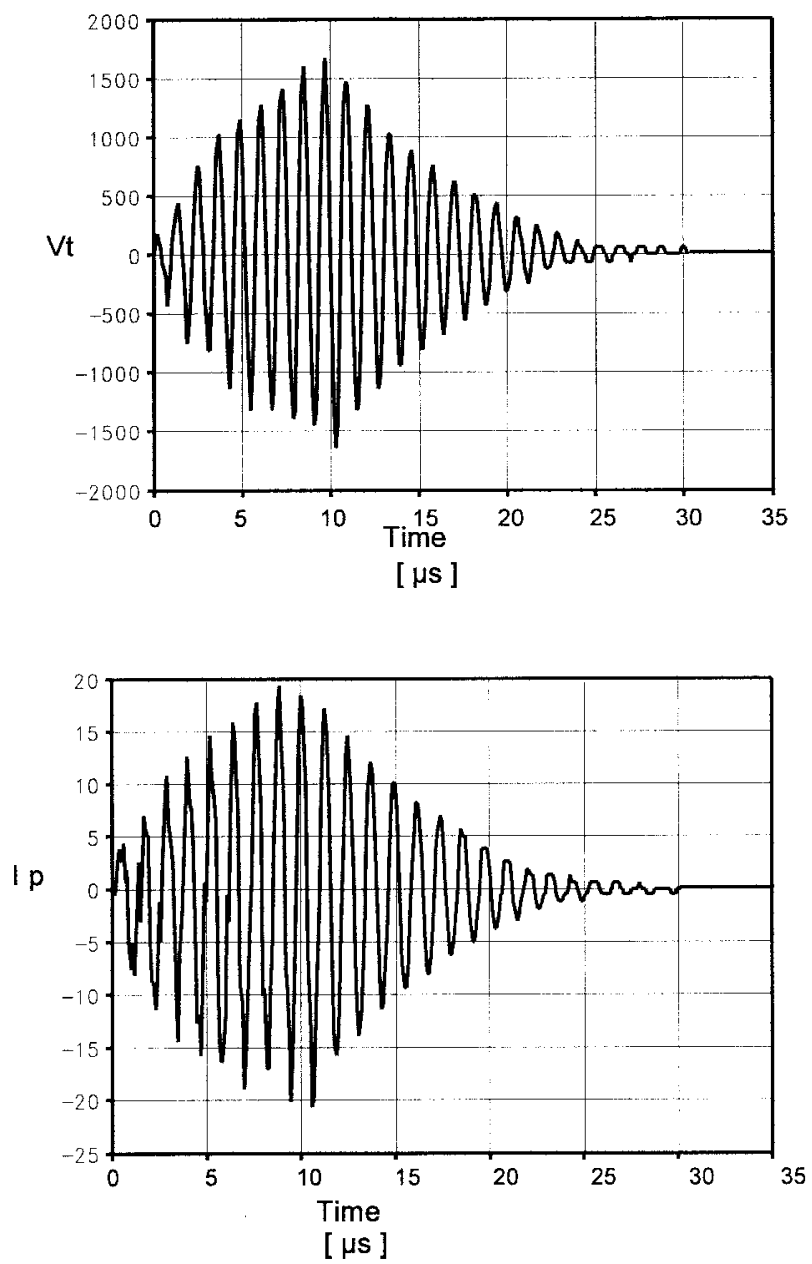

Fig. 8. The experimentally measured primary voltage and the current of the transformer when the secondary is open circuit.

The U52-cored transformer has marginally lower resistance than the other magnetic-cored transformers and, consequently, has the lowest overall losses.

\section{EXPERIMENTAL RESULTS}

An experimental circuit, similar to Fig. 4, was built to verify the simulated results. The high-current converter is an inverter dc welder, followed by a low-frequency inverter to alternate the electrode polarity for aluminum tungsten inert gas (TIG) welding. The voltage on the transformer is measured, rectified, and then compared to a reference voltage in the control circuit. The transformer voltage amplitude increases exponentially and, when it exceeds the reference voltage, the converter is switched off for a period. This dead time is typically twice as long as the active interval. During the plasma condition, the low impedance of the load prevents the output voltage reaching the turnoff reference voltage, and a time-out circuit activates the dead interval.

Experimental results of the open-circuit output voltage and current through the primary of the transformer are shown in Fig. 8. The primary voltage and current of the transformer when the secondary is short circuited are shown in Fig. 9.
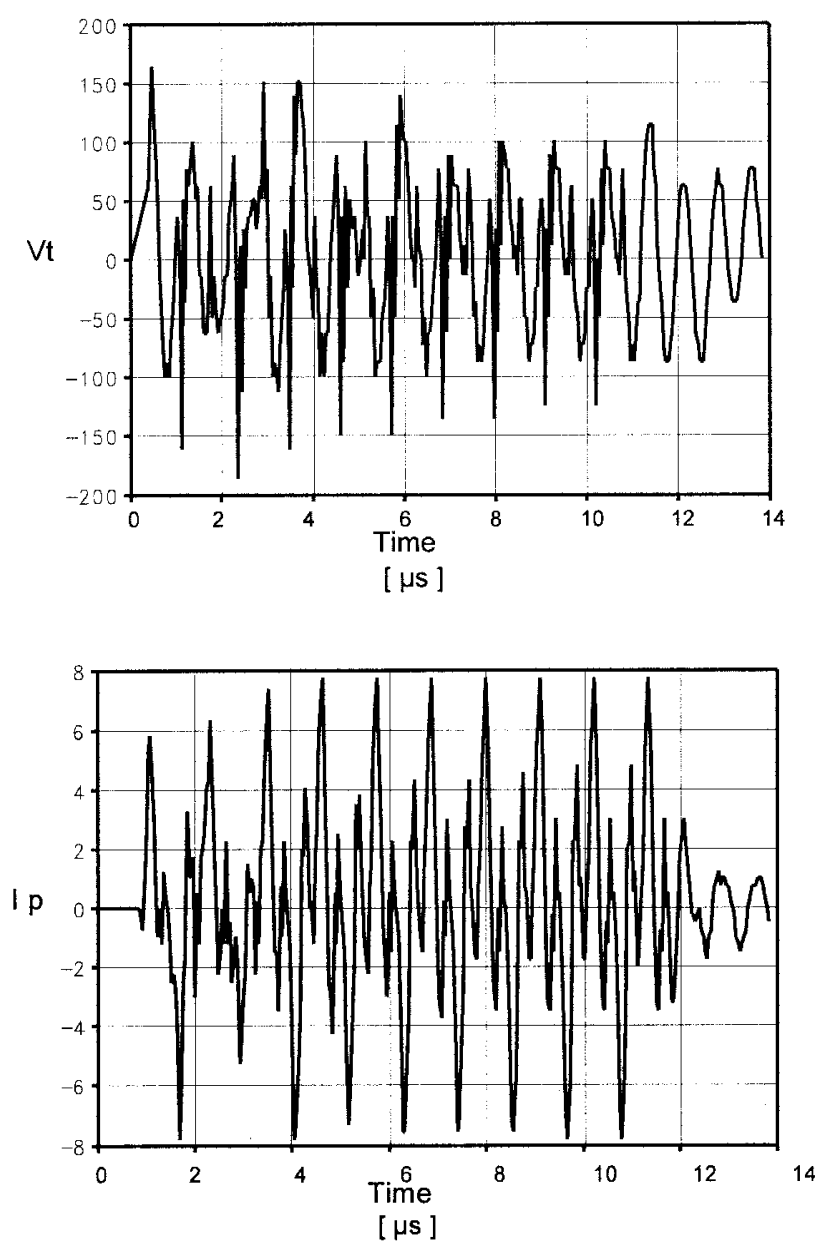

Fig. 9. The experimentally measured primary voltage and the current of the transformer when the secondary is short circuit.

Similar waveforms and wave amplitudes were observed during welding.

The values of the components are as follows:

$$
\begin{aligned}
& \text { E65-core transformer } \\
& C 1=C 2=1 \mathrm{nF} \\
& V_{d}=310 \mathrm{~V}(\text { rectified } 220 \mathrm{~V} / 50 \mathrm{~Hz}) \\
& L_{1}=16 \mu \mathrm{H} \\
& L_{2}=5 \mu \mathrm{H} \\
& \text { duty cycle }=10 \% \\
& \text { switching frequency }=800 \mathrm{kHz} \\
& \text { turns ratio }=7: 7 .
\end{aligned}
$$

The input power, measured on the dc supply while the secondary of the transformer was open circuit (Mode 1), was $65 \mathrm{~W}$. When the secondary of the transformer was short circuited, the measured converter losses were $16 \mathrm{~W}$. Since load does not absorb power, these figures correspond to the total losses in the circuit.

\section{CONCLUSION}

A number of possible composite topologies using separate high-current and high-voltage converters were investigated, with arc plasma power supplies in mind. The most suitable 
series resonant converter circuit for the high-voltage ac source, which is connected in series with the main high-current power supply, is the parallel inductive-loaded topology.

The transformer of the arc striking converter is subjected to very special circuit conditions. The elements of the equivalent transformer circuit are different for the two operating modes of the converter, due to the saturation of the core and the large amount of eddy-current losses in the secondary. This makes analysis very difficult, and the experimental route has been followed.

Four different transformers using an E core, I core, U cores , and an air core were designed and constructed. All of them functioned satisfactorily, and differences in efficiency and overall performance were found to be less important than other considerations, such as weight, manufacturability, and cost.

A burst control was introduced to reduce the heating of the core. The design and implementation and experimental results of an $800-\mathrm{kHz} 2-\mathrm{kV}$ arc-striking converter suitable for welding application has been described.

\section{APPENDIX}

A method to experimentally determine the equivalent series resistance and inductance of the transformer during Modes 1 or 2 is described. As can be seen in Fig. 5, the equivalent circuit comprises an equivalent inductance, capacitor, and resistance, all connected in series to a square-wave power supply. The only differences between the equivalent circuit during each mode of operation are the values of the equivalent inductance and resistance. The current through the equivalent inductance and the voltage over the capacitor are given in (8) and (9).

The equivalent inductance and resistance of each transformer during each mode of operation can be determined from the experimental waveform by measuring at the exponential decay of the voltage, immediately after the converter is switched off. From (8) and (9), the following two equations can be derived:

$$
\begin{aligned}
L_{\mathrm{eq}} & =\frac{t_{2}-t_{1}}{\ln \left(\frac{V_{t}\left(t_{2}\right)}{V_{t}\left(t_{1}\right)}\right)(C 1+C 2)+\left(t_{2}-t_{1}\right) \omega_{d}^{2}(C 1+C 2)} \\
R_{\mathrm{eq}} & =\frac{2 \sqrt{L_{\mathrm{eq}}-\omega_{d}^{2} L_{\mathrm{eq}}^{2}(C 1+C 2)}}{\sqrt{C 1+C 2}}
\end{aligned}
$$

where $t_{1}$ is the time instant of the first voltage peak and $t_{2}$ is the the time instant of a voltage peak when the amplitude has decayed substantially.

\section{REFERENCES}

[1] L. Jeffus and H. V. Johnson Welding Principles and Applications, 2nd ed. Albany, NY: Delmar, 1988, pp. 320-340.

[2] H. Akagi and A. Nabae "A voltage inverter using IGBT's for a $50 \mathrm{kHz}$ $10 \mathrm{kV}$ corona surface treater," in Conf. Rec. IEEE-IAS Annu. Meeting, Oct. 1989 , pp. $213-220$.

[3] F. E. Abdel-Kader and A. A. Mohamed, "Welding transformer control by the electronic control of the leakage flux," Elect. Mach. Power Syst., vol. 21 , no. 2, pp. 217-227, 1993.

[4] R. L. Steigerwald, "A comparison of half-bridge resonant converter topologies," IEEE Trans. Power Electron., vol. 3, pp. 111-120, Apr. 1986.

[5] P. C. Theron, J. A. Ferreira, J. C. Fetter, and H. W. E. Koertzen, "Welding power supplies using the partial series resonant converter," in Proc. IEEE IECON'93, 1993, pp. 1319-1324.

[6] L. Malesani, P. Mattavelli, L. Rossetto, P. Tennti, W. Marin, and A. Pollmann, "Electronic welder with high-frequency resonant inverter," in Conf. Rec. IEEE-IAS Annu. Meeting, Oct. 1993, pp. 1073-1080.

[7] G. B. Joung, C. T. Rim, and G. H. Cho, "Modeling of quantum series resonant converters-Controlled by integral cycle mode" in Conf. Rec. IEEE-IAS Annu. Meeting, Oct. 1988, pp. 822-826.

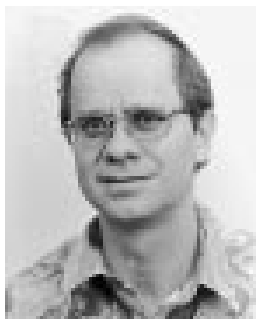

Jan A. Ferreira (M'88) was born in Pretoria, South Africa, in 1958. He received the B.Eng., M.Eng., and D.Eng. degrees in electrical engineering from Rand Afrikaans University, Johannesburg, South Africa, in 1980, 1982, and 1988, respectively.

In 1981, he was with the Institute of Power Electronics and Electric Drives, Technical University of Aachen, Aaachen, Germany, and worked in industry from 1982 to 1985 . From 1986 to 1997, he was with the Faculty of Engineering, Rand Afrikaans University, where he held the Carl and Emily Fuchs Chair of Power Electronics. Since 1998, he has been a Professor at the Delft University of Technology, Delft, The Netherlands. He is the author or coauthor of numerous technical papers. His research interests include magnetics, power electronics, and manufacturing technology.

Prof. Ferreira has served as Chairman of the IEEE South Africa Section and the South African Joint Energy Chapter of the IEEE.

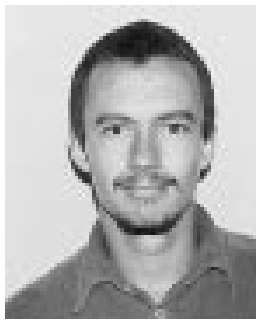

Johannes A. Roux was born in Thabazimbi, South Africa, in 1972. He received the B.Eng. and M.Eng. degrees in electrical engineering from Rand Afrikaans University, Johannesburg, South Africa, in 1993 and 1995, respectively.

In January 1996, he joined Research and Development, Iron and Steel Corporation of South Africa, Pretoria, South Africa, where he is currently an Electrical Engineer. $\mathrm{He}$ has authored two technical papers presented at conferences. 